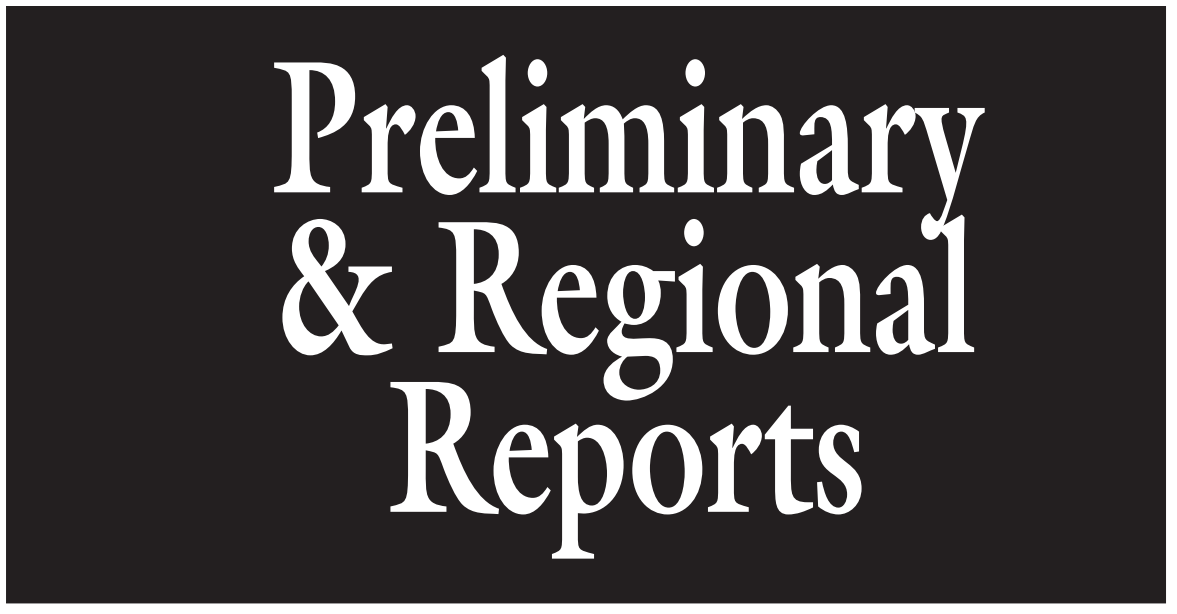

\section{Effect of Water Stress on Ginsenoside Production and Growth of American Ginseng}

\section{Wansang Lim ${ }^{1}$, Kenneth W. Mudge ${ }^{2}$, and Jin Wook Lee ${ }^{2}$}

\begin{abstract}
AdDitional INDEX wORDs. HPLC, drought, secondary metabolite, physiology, water potential, Panax quinquefolium

SumMARY. We determined the effect of moderate water stress on the growth of american ginseng (Panax quinquefolium), and on concentrations of six major ginsenosides (Rgl, Re, Rb1, Rc, Rb2, and Rd). Two-year-old "rootlets" (dormant rhizome and storage root) were cultivated in pots, in a cool greenhouse $\left(18.3 \pm 2{ }^{\circ} \mathrm{C}\right)$. Pots were watered either every 5 days (control) or every 10 days (stress), repeatedly for 8 days. Soil volumetric water content was measured during the last 10 days of the experiment for both treatments. Leaf water potential, measured on the last day of the experiment, was $-0.43 \mathrm{MPa}$ for the control and $-0.83 \mathrm{MPa}$ for the stress treatment. Drought stress did not affect above-ground shoot or root dry weight. Initial rootlet fresh weight (covariate) had a significant effect on the concentration of ginsenosides $\mathrm{Re}, \mathrm{Rb} 1, \mathrm{Rc}$, and $\mathrm{Rb} 2$. Drought stress increased the concentration of ginsenosides $\mathrm{Re}, \mathrm{Rbl}$, and total ginsenoside concentration.
\end{abstract}

$\mathrm{F}$ or thousands of years, asian ginseng (Panax ginseng) has been used medicinally in Asian countries as an "adaptogen" or tonic (Proctor and Bailey, 1987; Vogler et al., 1999). The american ginseng, the subject of the present study, is also used medicinally in both Asia and the West $(\mathrm{Li}, 1995$; Proctor and Bailey, 1987). A group of triterpene saponins known as ginsenosides are thought to be the principal pharmacologically active components of ginseng (Nam et al., 1998; Proctor and Bailey, 1987). It is well established in the biomedical

${ }^{1}$ Department of Plant Breeding and Genetics, Cornell University.

${ }^{2}$ Department of Horticulture, Cornell University, Ithaca, NY 14853 (tel. 607.255.1794; fax 607.255.9998; e-mail: kwm2@cornell.edu). literature that ginsenosides differ in their effects on mammalian physiology (Inhee et al., 2001; Murphy, 2000; Zhang and $\mathrm{Li}, 1998$ ). Hence genetic and environmental factors that affect not only total ginsenoside concentration but also the relative concentration (profile) of individual ginsenosides are of interest pharmacology and potentially in the marketing of american ginseng.

Differences in ginsenoside profiles among both cultivated and wild populations have been demonstrated (Assinewe et al., 2003; Betz et al., 1984; Foster, 1996; Lui and Staba, 1980; Mizuno et al., 1994; Tanaka, 1987), but the relative contribution of genetic and environmental factors could not be determined in these studies because distinct populations were not growing in a common environment (i.e., population origin was confounded by environmental differences). By transplanting several wild populations that differed in ginsenoside profile to each of two environmentally different forest gardens, we have shown in a previous experiment that both genetic and environmental factors (depending on the particular ginsenoside) influenced ginsenoside concentration ( $\mathrm{Lim}, 2005$; Lim et al., 2005).

Morphologically, american ginseng consists of an underground rhizome attached to a storage root (known collectively as a "rootlet"). A terminal, below-ground, dormant bud is set in late summer, from which the entire above-ground portion of the plant will emerge the following spring. The emergent stalk or "sympodium," which consists of fused petioles, bears one to four, or occasionally more, palmately compound leaves (the number is more or less age-dependent) known as "prongs" and a terminal inflorescence. After the emergence and enlargement of these structures in the spring (complete in approximately 4 weeks) this highly determinant species undergoes no further above-ground growth until the next growing season (Anderson et al., 1993).

In North America, american ginseng is cultivated either under natural forest shade ("woods-grown" production), especially in the northeastern

\begin{tabular}{llll}
\hline $\begin{array}{l}\text { Units } \\
\text { To convert U.S. to SI, } \\
\text { multiply by }\end{array}$ & U.S. unit & SI unit & $\begin{array}{l}\text { To convert SI to U.S., } \\
\text { multiply by }\end{array}$ \\
\hline 0.1013 & atmosphere $(\mathrm{s})$ & $\mathrm{MPa}$ & 9.8692 \\
29,574 & $\mathrm{fl} \mathrm{oz}$ & $\mu \mathrm{L}$ & $3.3814 \times 10^{-5}$ \\
29.5735 & $\mathrm{fl} \mathrm{oz}$ & $\mathrm{mL}$ & 0.0338 \\
3.7854 & gal & $\mathrm{L}$ & 0.2642 \\
2.54 & inch(es) & $\mathrm{cm}$ & 0.3937 \\
25.4 & inch(es) & $\mathrm{mm}$ & 0.0394 \\
1 & micron & $\mu \mathrm{m}$ & 1 \\
28.3495 & $\mathrm{oz}$ & $\mathrm{g}$ & 0.0353 \\
28,350 & $\mathrm{oz}$ & $\mathrm{mg}$ & $3.5274 \times 10^{-5}$ \\
$\left({ }^{\circ} \mathrm{F}-32\right) \div 1.8$ & $\mathrm{o}$ & ${ }^{\circ} \mathrm{C}$ & $\left(1.8 \times{ }^{\circ} \mathrm{C}\right)+32$ \\
& & &
\end{tabular}


U.S., or under artificial shade ("field" production), mostly in Ontario, Wisconsin, and British Columbia. Field cultivation-but not woods-grown cultivation-often involves irrigation, especially in drier production areas [e.g., British Columbia (British Columbia Ministry of Agriculture Food and Fisheries, 2003)]. Field cultivation usually involves higher planting density than forest cultivation.

Various environmental factors, including soil nutrients (Konsler et al., 1990; Li and Mazza, 1999), mulching (Zito et al., 1986), and irradiance (Fournier et al., 2003) affect ginsenoside concentration, but not all ginsenosides respond in the same way to any given environmental variable. For example, the red : far red ratio affected Rd, Rc, and Rgl, but not Rbl, Re, and Rb2 (Fournier et al., 2003). Although soil moisture affects ginseng yield $(\mathrm{Li}$ and Berard, 1998; Park, 1980, 1982a, $1982 b, 1996)$, the only suggestion that soil moisture may affect ginsenoside concentration is found in a report by Lee et al. (1987). Based on a survey of asian ginseng harvested from many commercial farms throughout Korea, these authors reported a negative correlation between "soil moisture" and "crude saponin" content (dry weight of an alcoholic root extract, which includes but is not limited to ginsenosides). Soil moisture content was not clearly defined by these authors.

Stress effects on secondary products have been documented in other species (Canter et al., 2005), including drought-induced elevation of the alkamide and phenolic acid contents of purple coneflower (Echinacea purpurea) (Gray et al., 2003), and of the saponin content of quinoa (Chenopodium quinoa) (Soliz-Guerrero et al., 2002). Similarly, saponin content was elevated as a result of osmotic stress in cell cultures of sanchi ginseng $(P$. notoginseng) (Zhang et al., 1995), and indole alkaloid content increased in response to osmotic shock in cell cultures of madagascar periwinkle (Catharanthus roseus) (Zhao et al., 2000). This experiment was undertaken to test the hypothesis that moderate drought stress will increase the concentration of one or more ginsenosides with or without affecting root yield. A complementary objective was to determine the impact of moderate drought stress on shoot and root growth. Our goal with this greenhouse experiment was to determine whether further investigation into the use of drought as a management tool for the optimization of ginsenoside concentration as a component of ginseng quality is warranted.

\section{Materials and methods}

Two-year-old dormant seedling rootlets of woods-cultivated american ginseng were purchased in Nov. 2002 , and stored at $4{ }^{\circ} \mathrm{C}$ for $1000 \mathrm{~h}$ to break dormancy. Each rootlet was transplanted to a 6 -inch-diameter plastic pot filled with $0.8 \mathrm{~L}$ of greenhouse potting mixture consisting of 1 peat moss:2 soil: 1 perlite (by volume). Plants of this highly determinate species were grown to full above-ground size for 1 month under well-watered conditions before the imposition of the experimental treatments.

The randomized complete-block design consisted of two irrigation treatments differing in the interval between rewatering [ $5 \mathrm{~d}$ (control) vs. $10 \mathrm{~d}$ (stressed)]. For each treatment there were three blocks corresponding to bench position along the east-west axis of the greenhouse. Each treatment consisted of 30 pots in each of the three blocks ( $\mathrm{n}=90$, for each treatment). Experimental treatments began on 8 Mar. and continued for $80 \mathrm{~d}$ through 16 cycles for the control, and eight for the stress treatment. Natural ambient lighting was supplemented with lowintensity lighting from incandescent bulbs to extend the photoperiod, which was adjusted weekly to approximate the natural photoperiod over the course of a normal outdoor growing season (mid-April through September).

For the last $10 \mathrm{~d}$ of the experiment (one and two cycles for the stress treatment and the control, respectively), volumetric water content (VWC) was measured on 20 individual plants (pots) per treatment, using a Theta Probe (Delta T Devices, Cambridge, U.K.). Available water content (AWC) was calculated as described by Fernandez et al. (2005) and Xue et al. (2002):

$$
\mathrm{AWC}=\frac{\left(\mathrm{VWC}_{a}-\mathrm{VWC}_{p w p}\right)}{\left(\mathrm{VWC}_{c c}-\mathrm{VWC}_{p w p}\right)} \times 100
$$

where the subscripts $a, c c$, and $p w p$ correspond to the actual water content at sampling, at container capacity $[\mathrm{CC}(100 \%$ AWC $)]$, and at permanent wilting point [PWP $(0 \%$ AWC)], respectively. We used the relationship between VWC and $\Psi_{\text {soil }}$ published earlier by Reeves and Whitlow (2004) for the same 1:2:1 greenhouse potting mix, which involved regression analysis of VWC (measured with a Theta probe) and $\Psi_{\text {soil }}$ (measured with a thermocouple psychrometer) on soil samples of known gravimetric soil moisture content. For purposes of calculating AWC using the above equation, we used the convention of $-0.03 \mathrm{MPa}$ as an estimate for $\Psi_{\text {soil }}$ at field capacity (Fernandez et al., 2005) as a proxy for $\Psi_{c c}$. This is only an approximation, since "container capacity" is similar but not identical to "field capacity" because of container-related factors affecting moisture distribution in containerized soils. We also used the convention of $-1.5 \mathrm{MPa}$ for $\Psi_{p w p}$ (Fernandez et al., 2005) These $\Psi_{\text {soil }}^{p w p}$ values for CC and PWP were used to derive $\mathrm{VWC}_{c c}$ and $\mathrm{VWC}_{p w p}$ from the data of Reeves and Whitlow (2004).

After $80 \mathrm{~d}$, the number of surviving plants for each treatment [control $(\mathrm{C})$ and stressed $(\mathrm{S})]$ in each block was $29 \mathrm{C}$ and $29 \mathrm{~S}$ for block $1 ; 30 \mathrm{C}$ and 29 $S$ for block $2 ; 29 \mathrm{C}$ and $30 \mathrm{~S}$ for block 3 . At the end of the last dry-down cycle (day 80 ), predawn leaf water potential $\left(\Psi_{\text {leaf }}\right)$ was determined for 20 plants per treatment using a pressure bomb (SoilMoisture, Santa Barbara, Calif.). All remaining plants were harvested to determine the fresh weight of the shoots (SRW) and roots (RFW), and roots were dried using a forced-air food dehydrator at $35{ }^{\circ} \mathrm{C}$ for $3 \mathrm{~d}$ for measurement of RDW. This method of drying by gentle heating - as opposed to freeze drying or forced-air drying at a higher temperature-was used because it more closely approximates the drying method used by ginseng collectors/growers.

After weighing, all dried roots were ground to a fine powder for ginsenoside analysis. Each root sample was stored in a separate airtight, sealed, glass scintillation vial, at room temperature. The procedure for ginsenoside extraction and analysis of each individual root was based on Court et al. (1996) as modified by Lim et al. (2005). A 100-mg powdered sample of each root sample was extracted in $10 \mathrm{~mL}$ of $100 \%$ high-performance liquid chromatography (HPLC)-grade methanol, in a sonicator for $15 \mathrm{~min}$ at room temperature. The sample tube was centrifuged at $3220 g_{\mathrm{n}}$ for $1 \mathrm{~min}$ and the supernatant was collected. The pellet was re-extracted two times with 
$10 \mathrm{~mL}$ of solvent each time, and the supernatants were combined. After reducing the supernatant to dryness under vacuum at $38{ }^{\circ} \mathrm{C}$, the residue was re-dissolved in $2 \mathrm{~mL}$ of $100 \%$ methanol. This solution was then dried under a stream of nitrogen $\left(\mathrm{N}_{2}\right)$ at $38^{\circ} \mathrm{C}$, and finally re-dissolved in 500 $\mu \mathrm{L}$ of $73 \%$ acetonitrile diluted with HPLC-grade water. A $15-\mu \mathrm{L}$ sample was injected for HPLC analysis (model 2690 separations module with a model 996 photodiode array; Waters Co., Milform, Mass.) to determine absorption at $203 \mathrm{~nm}$. Empower Pro software (build 1154; Waters Co.) was used for gradient programming and integration of absorption peaks. An HPLC column (Chromapack standard columns, LiChrosorb RP18, $5 \mu \mathrm{m}, 250 \mathrm{~mm} \times$ $3 \mathrm{~mm}$; Varian, Palo Alto, Calif.) was used with a guard column (Chromsep Guard R; Varian) having a gradient of two solvents-(A) phosphate buffer $\left(\mathrm{KH}_{2} \mathrm{PO}_{4}, \mathrm{pH} 5.8,10.3 \mathrm{~mm}\right)$ and $(\mathrm{B})$ acetonitrile: $0-20 \mathrm{~min}, 84 \%$ to $82 \% \mathrm{~A}$, $16 \%$ to $18 \% \mathrm{~B} ; 20-60 \mathrm{~min}, 82 \%$ to $60 \%$ A, $18 \%$ to $40 \%$ B, at a flow rate of 1.15 $\mathrm{mL} \cdot \mathrm{min}^{-1} \cdot \mathrm{M}$-cresol was used as an internal standard. Ginsenoside standards included $\mathrm{Rg} 1$, Re, Rbl, Rc, Rb2, and Rd (Indofine Chemical Co., Hillsborough, N.J.). Qualitative identification of ginsenoside peaks was determined by co-chromatography (equivalent retention time) with chemically pure standards, and quantification was based on the integration of peak area compared with a standard curve.

The statistical analysis of the VWC of the dependent variables, $\Psi_{\text {soil }}$, predawn $\Psi_{\text {leaf }}$, above-ground SFW, RFW, and RDW, and for the concentration of each of the six ginsenosides was performed using analysis of covariance with the GLM procedure of SAS (version 8.2; SAS Institute, Cary, N.C.) to evaluate variation between treatments (control and stressed) using the initial fresh weight (IFW) as a covariate. Initially the statistical model included block, treatment, IFW, and interactions. For each dependent variable there was no significant block effect, so the analyses were rerun without block in the model. Statistical significance presented in Table 1 is based on these latter (iterative) analyses. If IFW or the interaction between IFW $x$ treatment was significant $(P \leq 0.05)$, the least squares mean for the average IFW $(0.87 \mathrm{~g})$ was used for ginsenoside concentration in Fig. 1.

\section{Results and discussion}

In an earlier attempt to test the effect of soil moisture on the growth of american ginseng under controlled conditions, Li and Berard (1998) maintained treatments at predetermined, minimally fluctuating soil moisture levels by weighing pots every $4 \mathrm{~d}$, and differentially rewatering each treatment to maintain $100 \%, 75 \%$, and $50 \%$ AWC. Their protocol resulted in less fluctuation in soil moisture over time than could be expected during actual field or forest ginseng production. The experiment reported here was designed to impose more realistic fluctuations in soil moisture for the two experimental treatments by irrigating to flow- through followed by rewatering pots on successive 5 -d (control) or 10-d (stressed) "dry-down" cycles. Table 1 shows that there was a two-fold difference in average soil VWC (measured with a Theta probe) between soils in the control treatment and those under the stressed treatment. The VWC of the control soils was slightly above (wetter than) the upper end of the seasonal range in VWC (16\% to $28 \%$ ) reported for field production of ginseng grown in semi-arid British Columbia (Bailey, 1990), whereas the VWC of soils in the stressed treatment $(17 \%)$ was at the low end of the seasonal range, but above the wilting point $(14 \%)$ reported by Bailey (1990).

Soil moisture expressed as a per-
Table 1. Effect of irrigation interval on soil moisture content, leaf water potential and growth of american ginseng in a greenhouse pot culture experiment.

\begin{tabular}{|c|c|c|c|c|c|c|c|}
\hline \multirow[b]{2}{*}{$\begin{array}{l}\text { Irrigation } \\
\text { interval }\end{array}$} & \multicolumn{3}{|c|}{ Soil moisture ${ }^{\mathrm{z}}$} & \multicolumn{4}{|c|}{ Plant growth and leaf water potentialy } \\
\hline & $\begin{array}{c}\text { VWC } \\
(\%)\end{array}$ & $\begin{array}{l}\mathrm{CC} \\
(\%)\end{array}$ & $\begin{array}{c}\text { AWC } \\
(\%)\end{array}$ & $\begin{array}{c}\text { SFW } \\
(\mathrm{g})\end{array}$ & $\begin{array}{l}\Psi \text { leaf } \\
\text { (MPa) }\end{array}$ & $\begin{array}{c}\text { RFW } \\
(\mathrm{g})\end{array}$ & $\begin{array}{c}\text { RDW } \\
(\mathrm{g})\end{array}$ \\
\hline $5-d$ & 32 & 68 & 65 & 1.01 & -0.43 & 2.92 & 1.05 \\
\hline $10-d$ & 17 & 39 & 25 & 1.05 & -0.83 & 2.68 & 1.03 \\
\hline Significance & ** & $--^{x}$ & --- & NS & * & NS & NS \\
\hline
\end{tabular}

${ }^{z}$ Soil moisture was measured directly as volumetric water content over the last $10 \mathrm{~d}$ of an 80 - $\mathrm{d}$ experiment for two successive 5-d dry-down cycles (control) or one 10-d dry-down cycle (drought stress). Percentage of container capacity (CC) and available water content (AWC) were calculated from soil volumetric water content (VWC) measurements, as described in the text.

${ }^{y}$ Effect of irrigation interval on shoot fresh weight (SFW), root fresh weight (RFW), and root dry weight (RDW), and on predawn leaf water potential $\left(\Psi_{\text {leaf }}\right)$ at the end of an 80-d experiment (16 successive 5-d dry-down cycles for the control, and eight successive 10-d dry-down cycles for the stress treatment). SFW, RFW, and RDW are the averages at the end of the 80 - $\mathrm{d}$ experiment; $1 \mathrm{~g}=0.0353 \mathrm{oz}, \mathrm{l} \mathrm{MPa}=9.8692$ atmospheres.

'Dashes (---) indicate that percent CC and AWC were not independently statistically analyzed because they were calculated based on direct measurement of VWC.

ss, ${ }^{*}{ }^{* *}$ Nonsignificant or significant at $P=0.05$ or 0.001 , respectively.

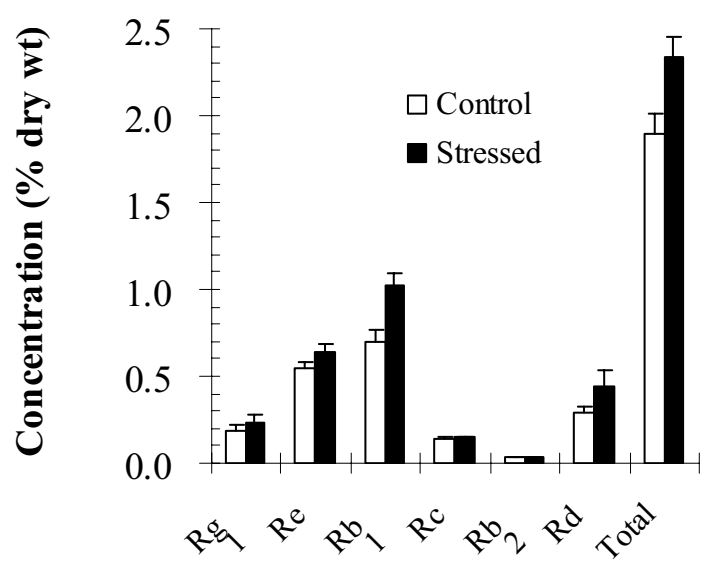

Gins enoside

Fig. 1. Effect of irrigation interval for 16 successive 5-d dry-down cycles (control) or eight successive 10-d dry-down cycles (stressed) on root ginsenoside concentration (percent dry weight) of american ginseng after $80 \mathrm{~d}$. Treatment means for ginsenosides $\mathrm{Rgl}$ and $\mathrm{Rd}$ are displayed because the covariate, initial fresh weight (IFW) was nonsignificant, whereas for Re, Rbl, Rc, and Rb2, LS means for the average IFW $[0.87 \mathrm{~g}(0.031 \mathrm{oz})]$ are displayed because the covariate IFW was significant (Table 2). Error bars represent SE. 
centage of container capacity (percentage of CC) in the control pots was $68 \%$. This is near the upper end of the range for optimum soil water content reported for asian ginseng ( $48.7 \%$ to $65.5 \%$ ) in previous studies (Mork and Son, 1981; Park, 1980), whereas the percentage of CC of soils in the pots of the stressed treatment (39\%) was lower than the optimum range, suggesting that plants in this treatment were being subjected to physiologically significant water stress. At the end of the dry-down cycles, soil water potential $\left(\Psi_{\text {soil }}\right)$ for the control (at an average of two 5-d cycles) was -0.1 MPa, compared with $-1.88 \mathrm{MPa}$ for the stressed treatment (one cycle; Fig. 2). The average AWC during the last dry-down cycle for the stressed treatment was considerably lower than for the control (65\%; Table $1)$. These values are within and below, respectively, the range determined by Li and Berard (1998) to be optimal for the growth of american ginseng.

Table 1 shows the plant growth response of ginseng plants after $80 \mathrm{~d}$ in either the control or the stressed treatment. There were no significant effects on growth in terms of aboveground SFW, RFW, or RDW. Predawn leaf water potentials on the last day of the experiment were $-0.43 \mathrm{MPa}$ for the control compared with -0.83 $\mathrm{MPa}$ for the drought stress treatment $(P<0.001)$. These levels suggest that even plants in the control may have been experiencing mild water stress, but that plants in the stress treatment were experiencing a greater (moderate) level of water stress. That shoot growth was unaffected by water stress is not surprising, considering the highly determinant nature of the above-ground shoot system of this perennial species and noting that all plants in this experiment were well watered for the first 4 weeks after planting. During that period, shoots had enlarged to their full size and no further shoot growth occurred due to the determinant above-ground shoot development of this species. The only increase in total plant biomass after an initial period ( $\leq 4$ weeks) of shoot emergence and elongation for this species is in the root system, with a minimal increase in growth of the underground rhizome. In this experiment, growth of the roots of plants in both treatments was not significantly different despite lower (more negative) leaf water potential in the less frequently watered treatment
(Table 1). The lack of difference in root growth between the two watering regimes despite significantly lower leaf water potential in the stress treatment is consistent with the results reported by $\mathrm{Li}$ and Berard (1998), who found that root growth response to soil moisture deficit depended on soil type. In a silty loam soil, roots grown at $25 \%$ and $50 \%$ AWC were significantly lower in root dry weight than those grown at $75 \%$ AWC, whereas in a sandy loam, no differences were observed among soil moisture regimes. The potting mix used in this experiment ( 1 peat moss : 2 soil : 1 perlite), is likely to have drainage characteristics more similar to the sandy loam than to the silty loam soil used by Li and Berard (1998).

Table 2 shows that four of the six ginsenosides analyzed ( $\mathrm{Re}, \mathrm{Rbl}, \mathrm{Rc}$, and $\mathrm{Rb} 2$ ), as well as the total of all six, were influenced by the covariate IFW. Only Re, Rbl, and total ginsenoside were elevated by the drought stress

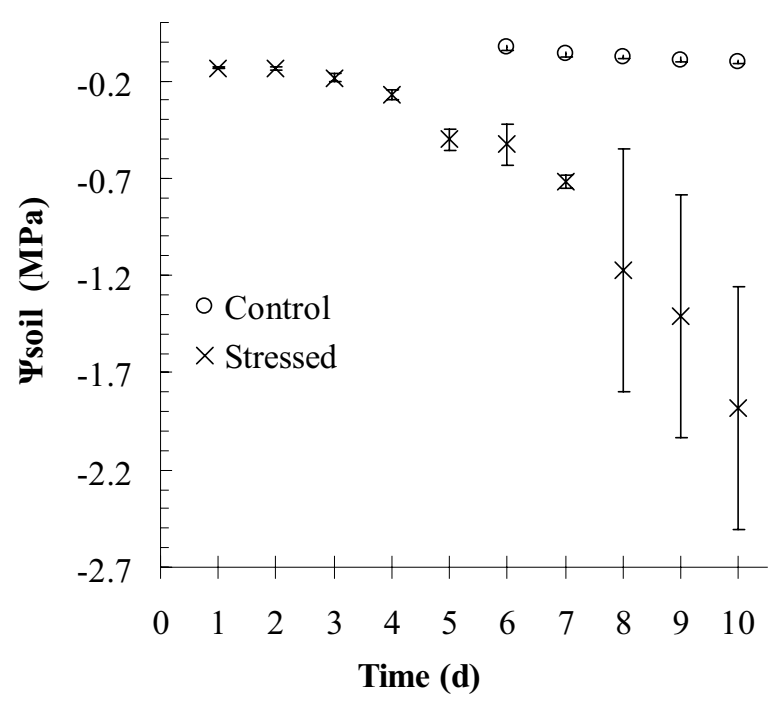

Fig. 2. Effect of irrigation interval for eight successive 10-d dry-down cycles [x (stressed)] or 16 successive 5-d dry-down cycles [o (control)] on soil water potential $\left(\Psi_{\text {soil }}\right)$ at the end of an 80-d experiment involving american ginseng. Error bars representing SE are shown only if greater than the size of the data symbol. During days 1-5 the o symbol (control) is "hidden" behind the $\mathrm{x}$ symbol (stressed); $1 \mathrm{MPa}=9.8692$ atmospheres.

Table 2. Significance levels from analysis of covariance for the effects of treatment (5-d control vs. 10-d stress irrigation interval) and the covariate, initial fresh weight (IFW), on root ginsenoside concentrations of american ginseng (as percentage of dry weight).

\begin{tabular}{lccccccc}
\hline & Rgl & Re & Rbl & Rc & Rb2 & Rd & Total $^{\mathrm{z}}$ \\
\hline Treatment (T) & NS & $*$ & $* *$ & NS & NS & NS & $* *$ \\
IFW & NS & $* *$ & $* *$ & $*$ & $*$ & NS & $* *$ \\
T $\times$ IFW & NS & NS & NS & NS & NS & NS & NS \\
\hline
\end{tabular}

${ }^{2}$ Total is the sum of six individual ginsenosides.

ss,, , * Nonsignificant or significant at $P=0.05$ or 0.01 , respectively. 
irrigation is not commonly practiced by woods-grown ginseng producers, periods of drought often occur at some point(s) during a growing season. With respect to the marketing of american ginseng, root shape is the primary factor in setting the price to growers, but ginsenoside content is a factor in retail marketing of ginseng by some growers and retailers. This is increasingly true when marketing to newly health-conscious North American and other consumers. There are numerous examples on the World Wide Web of ginseng marketing based in part on ginsenoside content (e.g., Harding's Ginseng Farm, 2003).

This report is the first demonstration of quantitative effects of drought stress on total ginsenoside concentration as well as on individual ginsenosides of american ginseng. We are aware of only one report regarding asian ginseng (Li and Berard, 1998), but in that study "drought stress" was not clearly defined. The results of this greenhouse pot experiment suggest that the effects of moderate drought on ginsenosides should be investigated further in outdoor production systems, especially since the ginsenoside-related response to post-emergent drought was not accompanied by a decline in root yield.

We have recently reported that both genetic and unspecified environmental factors (depending on the ginsenoside in question) are associated with variation in ginsenoside concentration among roots of eight different wild ginseng populations, each of which were transplanted to two different forest gardens (Lim et al., 2005). In that experiment, we found environmental but not genetic variation for Rbl, which is the same ginsenoside that exhibited the greatest magnitude of stress-induced increase in this greenhouse pot experiment. On the other hand, in the case of the $\operatorname{Re}$ (the other ginsenoside that exhibited a stress-induced increase in this experiment), we found that wild populations exhibited only genetic, but not environmental, effects (Lim et al., 2005). Seedlings used in the two distinct experiments were from different seed sources (genotypes), which might account at least partially for the difference in the response of Re. In a study by Fournier et al. (2003), natural variation in irradiance was shown to influence ginsenoside concentration. The results of the experiment reported here suggest that soil moisture is another environmental factor that, in addition to irradiance and soil nutrients (Konsler et al., 1990), may affect ginsenoside concentration under cultivated (outdoor) conditions. Additional field studies under irrigated (field production) or nonirrigated (woods-grown) conditions are warranted to determine whether moderate drought stress could be used as a management tool in the production of high-quality american ginseng.

\section{Literature cited}

Anderson, R., J.S. Fralish, J.E. Armstrong, and P.K. Benjamin. 1993. The ecology and biology of Panax quinquefolium L.(Araliaceae) in Illinois. Amer. Midland Naturalist 129:357-372.

Assinewe, V., B.R. Baum, D. Gagnon, and J.T. Arnason. 2003. Phytochemistry of wild populations of Panax quinquefolius L. (north american ginseng). J. Agr. Food. Chem. 51:4549-4553.

Bailey, W.G. 1990. The adaptation of ginseng production of semi-arid environments: The example of British Columbia, Canada. Korean J. Ginseng Sci. 14:297-309.

Betz, J.M., A.H. DerMarderosian, and T. Lee. 1984. Continuing studies on the ginsenoside content of commercial ginseng products by TLC and HPLC, II. Proc. 6th North Amer. Ginseng Conf. p. $65-83$.

British Columbia Ministry of Agriculture Food and Fisheries. 2003. Ginseng production guide for commercial growers. 9 Jan. 2006. <http://www.agf.gov.bc.ca/ speccrop/ginseng/ginseng_production_guide.htm>.

Canter, P.H., H. Thomas, and E. Ernst. 2005. Bringing medicinal plants into cultivation: Opportunities and challenges for biotechnology. Trends Biotechnol. 23:180-185.

Court, W.A., J.G. Hendel, and J. Elmi. 1996. Reversed-phase high-performance liquid chromatographic determination of ginsenosides of Panax quinquefolium. J. Chromatography A. 755:11-17.

Fernandez, M.D., M. Gallardo, S. Bonachela, F. Orgaz, R.B. Thompson, and E. Fereres. 2005. Water use and production of a greenhouse pepper crop under optimum and limited water supply. J. Hort. Sci. Biotechnol. 80:87-96.
Foster, S. 1996. American ginseng. 4 Jan. 2006. <http://www.herbalgram.org/default.asp?c=american_ginseng $>$.

Fournier, A., J.T.A. Proctor, L. Gauthier, S. Khanizadeh, A. Belanger, A. Gosselin, and M. Dorais. 2003. Understory light and root ginsenosides in forest-grown Panax quinquefolius. Phytochemistry 63:777-782.

Gray, D.E., S.G. Pallardy, H.E. Garrett, and G. Rottinghaus. 2003. Acute drought stress and plant age effects on alkamide and phenolic acid content in purple coneflower roots. Planta Medica 69:50-55.

Harding's Ginseng Farm. 2003. Welcome to Harding's Ginseng Farm. 9 Jan. 2006. <http://www.hardingsginsengfarm. $\mathrm{com} />$.

Inhee, M.J., H.S. Hong, J.H. Boo, K.H. Lee, S.H. Yun, M.Y. Cheong, I. Joo, K. Huh, and M.W. Jung. 2001. Ginsenoside $\mathrm{Rbl}$ and $\mathrm{Rgl}$ improve spatial learning and increase hippocampal synaptophysin level in mice. J. Neuroscience Res. 63:509-515.

Konsler, T.R., S.W. Zito, J.E. Shelton, and E.J. Staba. 1990. Lime and phosphorus effects on american ginseng II. Root and leaf ginsenoside content and their relationship. J. Amer. Soc. Hort. Sci. 115:575-580.

Lee, M.K., H. Park, and C.H. Lee. 1987. Effect of growth conditions on saponin content and ginsenoside pattern of Panax ginseng. Proc. Korea-Japan Panax Ginseng Symp. p. 89-107.

Li, T.S.C. 1995. Asian and american ginseng. A review. HortTechnology. $5: 27-34$

Li, T.S.C. and R.G. Berard. 1998. Effects of soil moisture on the growth of american ginseng (Panax quinquefolium L.). J. Ginseng Res. 22:122-125.

Li, T.S.C. and G. Mazza. 1999. Correlations between leaf and soil mineral concentrations and ginsenoside contents in american ginseng. HortScience 34:85-87.

Lim, W.S. 2005. Effects of interactions among age, cultivation method (location) and population on ginsenoside content of wild Panax quinquefolium L., one year after transplanting from wild. Korean J. Medicinal Crop Sci. 13:254-261.

Lim, W., K.W. Mudge, and F. Vermeylen. 2005 . Effects of population, age, and cultivation methods on ginsenoside content of american ginseng (Panax quinquefolium). J. Agr. Food Chem. 53:8498-8505.

Lui, J.H.C. and E.J. Staba. 1980. The ginsenosides of various ginseng plants and selected products. J. Natural Products (Lloydia). 43:340-346. 
Mizuno, M., Y. Junko, and T. Hirofumi. 1994. Differences in immunomodulating effects between wild and cultured Panax ginseng. Biochem. Biophys. Res. Commun. 200:1672-1678.

Mork, S.K. and S.Y. Son. 1981. Root and top growth of Panax ginseng at various soil moisture regimes. Korean J. Crop Sci. 26:115-120.

Murphy, L. 2000. Effects of american ginseng on breast cancer and prostate cancer cells. Proc. Amer. Ginseng Production in the 21st Century. p. 39-45.

Nam, K.Y., S.R. Ko, and K.J. Choi. 1998. Relationship of saponin and non-saponin for the quality of ginseng. J. Ginseng Res. 22:272-283.

Park, H. 1980. Water physiology of Panax ginseng. I. Habitat observation. Cultural experience, weather factors and characteristics of root and leaf. Korean J. Ginseng Sci. 4:197-221.

Park, H. 1982a. Water physiology of Panax ginseng II. Characteristics of reproductive organs and precipitation rate and humidity of shade system. Korean J. Ginseng Sci. 6:84-99.

Park, H. 1982b. Water physiology of Panax ginseng. III. Soil moisture, physiological disorder, diseases, insects and quality. Korean J. Ginseng Sci. 6:168-203.
Park, H. 1996. Research on ginseng production during the past 20 years. Korean J. Ginseng Sci. 20:472-500.

Proctor, J.T.A. and W.G. Bailey. 1987. Ginseng: Industry, botany, and culture. Hort. Rev. 9:187-236.

Reeves, M.E. and T.H. Whitlow. 2004. Physiological responses of red and freeman maples to water deficit stress. Acta Hort. 630:185-190.

Soliz-Guerrero, J.B., D.J. Rodriguez, R. Rodriguez-Garcia, J.L. Angulo-Sanchez, and G. Mendez-Padilla. 2002. Quinoa saponins: Concentration and composition analysis. Proc. 5th Natl. Symp. New Crops and New Uses: Strength in Diversity. p. 110-114.

Tanaka, O. 1987. Solubilizing properties of ginseng saponins. Proc. Korea-Japan Panax Ginseng Symp. p. 67-74.

Vogler, B.K., M.H. Pittler, and E. Ernst. 1999. The efficacy of ginseng. A systematic review of randomized clinical trials. European J. Clinical Pharmacology 55:567-575.

Xue, Q., M. Soundararajan, A. Weiss, T.J. Arkebauer, and P.S. Baenziger. 2002. Genotypic variation of gas exchange parameters and carbon isotope discrimination in winter wheat. J. Plant Physiol. 159:891-898.
Zhang, J. and J. Li. 1998. Ginsenoside Rgl is an anti-apoptotic agent. Proc. 7th Intl. Symp. on Ginseng. p. 12-20.

Zhang, Y.-H., J.J. Zhong, and J.T. Yu. 1995. Effects of osmotic pressure on cell growth and production of ginseng saponin and polysaccharide in suspension cultures of Panax notoginseng. Biotechnol. Lett. 17:1347-1350.

Zhao, J., W.H. Zhu, Q. Hu, and Y.Q. Guo. 2000. Improvement of indole alkaloid production in Catharanthus roseus cell cultures by osmotic shock. Biotechnol. Lett. 22:1227-1231.

Zito, S.W., J. Cheung, T.R. Konsler, and E.J. Staba. 1986. The effect on ginsenoside content of american ginseng (Panax quinquefolius L.) by type of bed mulch and by plant spacing through seven growing seasons. Proc. 7th North Amer. Ginseng Conf. p. 13-15. 